knowledge. We invest heavily in the development of question material and the processes of paper setting, quality assurance and standard setting to achieve this, as the SCEs are 'high stakes' and have direct and important consequences for career progression.

Development of the 12 SCEs started from scratch in 2007, and since then, the Federation of Royal Colleges of Physicians of the UK has invested over $£ 1.7$ million in developing these examinations. Over 18000 questions have been written, edited, peer reviewed and banked, 58 papers have been set and standard set, and the performance of 9200 questions has been analysed.

The SCEs are comparable in price with other specialty examinations when differences in the number of questions are taken into consideration, and we consider them to be good value for money. Although the European Diploma in Respiratory Medicine costs less, it is for established specialists rather than those in training and only contains 90 questions. More closely comparable accreditation examinations in the USA cost over $£ 1000 .^{2}$

We are aware of trainee concern about fees, and in response published some specific FAQs on our website in 2012 to improve transparency. ${ }^{3}$ Moreover, SCE fees were frozen in 2014 for the 2 nd year running, acknowledging that the financial environment is difficult for trainees.

We would like to reassure all candidates

Trainee concerns regarding the Specialty Certificate Examination: results of a British Thoracic Society national survey: MRCP (UK) response

We read with interest the results of the British Thoracic Society's national survey related to the specialty certificate examination (SCE) in respiratory medicine. ${ }^{1}$ We are pleased that trainees felt the SCE to be appropriate in difficulty, content and duration, and that our test centres were fit for purpose. This correlates with the results of the routine surveys we run after each examination, which also ask about quality of examination material and administration. We regularly monitor this important feedback from our candidates and make improvements in response.

When trainees take and pass an examination they want to know that it is a reliable, valid and fair test of their 
To cite Mucklow J, Elder A, Wheaton L, et al. Thorax 2014;69:771-772.

Received 28 January 2014

Accepted 29 January 2014

Published Online First 21 February 2014

\section{(S) Linked}

- http://dx.doi.org/10.1136/thoraxjnl-2013-204306

Thorax 2014;69:771-772.

doi:10.1136/thoraxjnl-2014-205180

\section{REFERENCES}

1 Patterson CM, Carter RI, Dodd JW, et al. Trainee concerns regarding the Specialty Certificate Examination: results of a British Thoracic Society national survey. Thorax 2014;69:85-86.

2 American Board of Internal Medicine. Take the Exam-Your Complete Guide. http://www.abim.org/ exam/cert-cost.aspx (accessed 15 Jan 2014).

3 MRCP (UK). SCE Financial FAQs. http://www.mrcpuk. org/document/sce-financial-faqs (accessed 15 Jan 2014). 